\title{
Virtual violence: cyberspace, misogyny and online abuse
}

\author{
Megan Todd
}

\section{Introduction}

As the twenty-first century continues its steady march, the internet has become an important part of daily life for much of the globe. Many of us shop, organise our finances, conduct our working lives, meet our intimate partners and maintain our relationships online. Technology has become increasingly affordable: tablets, smartphones and laptops are enabling more and more people in ever-remote areas to become 'switched on'. This has brought us to an interesting moment, where the issue of sexualised threats in online public spaces is a concern facing more and more women, yet it is drastically under-theorised. This chapter offers some ways to think through the issue.

Social networking sites such as Facebook and Twitter have become essential tools for negotiating both public and private lives in the last decade. The ways in which women, especially young women, are responded to and represented in such online spaces indicate the ways in which patriarchy (Walby 1990) and the 'male gaze' (where men (and women) are encouraged to gaze at women's bodies from a masculine point of view, a view which is voyeuristic, fetishistic and sadist) still holds sway (Mulvey 1975). In many respects, online abuse is one of the clearest manifestations of the spectrum of sexism and sexual harassment that exists within our society, part of Kelly's (1988) 'continuum of violence'. In other words, I argue it is an old story with a new face. The growing reach of the internet, and the rapid rise of new technologies, have provided new tools to inflict further violence 
against women and girls. Cyber violence against women and girls has now been widely acknowledged, by institutions such as the United Nations (2015), as an issue of global concern, adversely affecting the societies and economies of countries across the world.

This chapter begins with a discussion of the important connections between online abuse and gendered violence more generally. It moves on to consider language, voice and the important ways in which talking about the virtual world and what happens there, frames our understandings of it. The chapter then discusses notions of space and place, how these contribute to responses to online abuse. This chapter also considers the issue in light of the very recent decision that Britain is to leave the EU. What issues does such a move pose, given the important role of EU initiatives in the attempt to tackle male violence against women and girls (MVAWG) more generally? However, this chapter will finish by asking how such technologies also offer hope, new opportunities to help in the fight to combat MVAWG.

\section{The Tangled Web We Weave: Unpicking the threads, making the connections}

As Mary Beard (2014) points out in her excellent BBC lecture, this problem is not confined to the internet; rather, it is part of a wider tradition of silencing women. Speech, and particularly political speech, has been designated a man's province (de Beauvoir 1973 [1949]). The disadvantages suffered by women in society carry over into online spaces; women are under-represented in virtual communities, these often being domains deemed to be masculine, and they are subject to a range of harassment and abuse. In other words, 
there is no disruption of the existing unequal societal gender system: on the contrary, it is reproduced online.

It is imperative, if we are to combat cybermisogyny, that we focus on the ways in which it overlaps with, indeed is part of, a wider societal culture of woman hating. Joining up some of the dots between different forms of men's violence against women allows us to see the full extent of violence experienced by women. It is no easy project however, as processes of denial and legitimation frequently serve to hide men's violence (Romito 2008). Uncovering these processes and making the connections has to be the first part of the task of combating MVAW. Those connections are about the forms of violence and abuse experienced, the language used to talk about such abuse and the ways in which spaces have been falsely separated, into public and private and virtual or 'real', with the effect of minimising the harms experienced by women.

The division of the social world into the public and private has already been persuasively challenged by feminists (Richardson and May 1999, Stanko 1985). Historically, the dichotomy between the public and the private, with regard to domestic violence, has often been reflected in the ambivalence of most agencies, including the police, towards getting involved in situations which occurred 'behind closed doors' away from public view (Y1lo and Bograd 1988). Violence in the home between intimates was frequently, and perhaps still is, perceived as different from violence against a stranger in a public place (Stanko 1985). The parameters of the 'family' were traditionally set aside as paradigmatically 'private' (Oakley 1981). 
This public/private binary has resulted in attitudes which rendered domestic violence as not 'real' police work and therefore not associated with criminal investigation, as police work was about maintaining public order, where domestic violence was about marriage counselling and social work and not appropriate to their role (Yllo and Bograd 1988). As Stanko (1985) and Fineman (1994) have pointed out, much domestic violence has been regarded as trivial, and to a certain extent even considered normal, inevitable and excusable, because it was also 'domestic'. Edwards (1986), for example, concluded from interviews with police officers that domestic violence was seen by many as a 'normal' part of family life and, thus, not a matter for their concern except in severe cases. There was, and perhaps still is, a covert toleration of domestic violence. While domestic violence continued to be seen as a 'private matter', it was virtually impossible to redefine it as criminal. The issue of privileging a 'private' domestic situation, where men are abusing women within a household, took much political campaigning on the part of feminists, in order to expose the hypocrisy and use of power against women's interests (Corrin 1996). As a result of feminist campaigning, both heterosexual and same-sex 'domestic violence' are now public crimes in most Western European countries, though attrition rates for prosecutions remain high.

\section{Gendered divisions and violence}


Online abuse, then, needs to be considered in the wider context of gendered divisions, where men and women are frequently represented in key institutions - such as the media as polar opposites, both in terms of personality, (the popular refrain being 'men are from Mars and women from Venus'), and sexuality, with men's sex presented as unproblematic and upfront, whereas women are seen as capricious and mendacious (Smart 1989). Ours is also a society where violence against women is normal, in that it happens to many women. Despite decades of campaigning, one in three women on the planet will be raped or beaten in their lifetime (One Billion Rising.org), and in the UK, on average, two women a week are killed by a male partner or former partner, yet rarely is this headline news (Povey 2005). This enduring problem has an impact: with MVAWG becoming an expression of, and contributing to, further gender inequality (Walby and Allen 2004).

\section{What's in a Name? The damage done by discursive manoeuvres}

MVAWG online is, in part, an issue of language and voice. Language holds a central position in framing, shaping and understanding social problems. As Letherby (2003) suggests, it is important to bear in mind the role language plays in the production and prevalence of masculinized 'knowledge'. Many theorists have argued that language is 'man-made' (Spender 1980, Smith 1988, Cameron 1992, Coates 1993) and that language thus reflects a male understanding of the world. It thus becomes important not to regard language as neutral and to give serious thought to the implications behind certain terms. 
For over thirty years feminists have highlighted the problematic nature of the language of abuse, from the distracting paedophile, which deflects attention from the fathers, uncles, brothers and grandfathers who abuse, to the minimising and normalising effects of marital abuse. Legal definitions of abuse, such as rape, have been accused of being too narrow, potentially omitting practices which many women would regard as violent (Walby 1990). Our common-sense (and very often legal) definitions of violence are, in fact, 'male definitions' restricted to the most extreme and public forms (Smart 1995). The very word violent was problematic, with feminists having a battle on their hands to widen narrow definitions, based on the idea that violence is a physical manifestation, to include emotional, sexual, financial, economic and psychological abuse.

This battle is an ongoing one with regard to online abuse, with many refusing to acknowledge the power of violence without physical expression. Indeed, language is no less a problem when it comes to online abuse, though what is missing from discussions about cyberabuse, is the gendered aspect of this practice and its repercussions. Frequently, the terms used disguise the gender of the perpetrator of online abuse, just as they do with other forms of abuse such as rape and domestic violence. Trolling - a form of cyberbullying - involves the sending and submission of provocative emails or posts with the intention of inciting angry responses. The person responsible, the troll, appears as a gender neutral being, despite the fact that the vast majority of them appear to have been male, and the vast majority of victims appear to be female. Code words effectively eliminate the gender and identity of the perpetrators of MVAW (Phillips and Henderson 1999). Dominant 
discourses around gender abuse, thus serve to degender the problem and (frequently) gender the blame (Berns 2001). Men disappear from view.

Another significant term is Fraping - this is the act of raping someone's Facebook profile when they leave it logged in; it is a portmanteau of Facebook and rape. The term is an offensive and dangerous one, which normalises online interactions which are violent and sexual, and trivialises the act of rape. Incidentally, as with 'real' rape, the victim of 'fraping' is frequently deemed culpable for what has happened to them. As with terms such as domestic violence, arranged marriage, honour killing or family conflict, the language used to describe cyberabuse, trolling, fraping, upskirting, masks the identity of the abuser, of the victim and very often masks that fact that any violence has occurred. This is potentially problematic because it may mean that victims are not able to access the help and support they need. Such words contribute to the shoring up of heteronormative relations and desensitises us to gendered violence.

\section{Space and place: the gendered constructions of cyberspace}

A similar challenge to the earlier public/private binary presents itself when considering the representation of online spaces. Firstly, the division between public and private is murky in new and complex ways. We live our lives on the internet nowadays, thus the boundaries between public and private have been further blurred and notions of both are transformed (Sheller and Urry 2003). Nevertheless, the internet is a gendered space, constructed as masculine. There is still a pronounced gender gap in internet use and access, though this is steadily lessening. Trolling, in particular, draws attention to the abuse and harassment 
experienced by women who dare to trespass into cyber spaces deemed to be a masculine province.

These women are castigated for daring to enter these spaces in much the same way as women in the nineteenth and early twentieth centuries caused anger for daring to ride bicycles because they would have greater independence and access to the 'male' public sphere. In attempts to dissuade them from cycling, Victorian women were told they might ruin their reproductive capabilities, become highly sexed or, even worse, become 'inverts'/lesbians. If moral ugliness weren't enough, it might also cause physical ugliness in the form of bicycle face (Malleson 2002). Online abuse serves a similar function in trying to curtail freedom of expression.

In addition, there is frequently a troubling distinction made between the online world and the so called 'real' world. The internet is frequently talked about in juxtaposition to the 'real' world, as if most of our lives aren't already an intertwinement of the online and offline. A by-product of drawing this distinction is that it undermines our thinking of the internet as a public space. However, the internet is very much a public space, with all of the same sexism, racism, homophobia, and transphobia of our streets and homes.

The inequalities women experience in society carry over into cyberspace, both through under-representation and through various forms of harassment and sexual abuse. In this respect, it becomes possible to see that the internet isn't the problem, cybermisogyny or, to introduce a contested but, I think, absolutely appropriate term, patriarchy is the problem. Blaming the internet for gender violence is a recuperative strategy for dominant discourse, 
taking the blame away from the abusers (Alcoff and Gray 1993). There is thus a tendency to minimise the impact of online abuse - 'it's just the internet' - just as rendering domestic violence to the private sphere served to minimise its impact.

\section{Cyberia: The cold realities of online misogyny}

Media, public and political attention to the plight women face online has increased in the past couple of years. The Guardian's project, The Web We Want (2016) and the cross-party public consultation campaign Reclaim the Internet (2016), have drawn attention to both the proliferation and the serious impact of misogynistic abuse directed at women online. The 'virtual' assaults experienced by women mean that spaces - such as Twitter - intended for debate are transformed into places where debate is closed off for women. High profile examples of online harassment, including the experience of Anita Sarkeesian, Caroline Criado-Perez and Mary Beard, make clear the ways in which women's voices are not welcomed. Women are, arguably, being deliberately targeted and intimidated. Games designer Brianna $\mathrm{Wu}$, working in a field where men have traditionally been held as experts, was advised by police to leave her home after receiving several detailed death threats. Writers such as Imani Gandy have spoken out about the sexist, racist abuse black women receive for deigning to have a presence on Twitter. A lot has been made, too, of some female MPs, such as Stella Creasy and Paula Sherriff, who have entered both the gendered sphere of politics as well as the gendered sphere of cyberspace and have faced the consequences. There are many who are quite willing to further contribute to minimising 
the harmful effects of online abuse. For instance, Brendan O'Neill (2011), writing for the Telegraph belittled attempts to combat cyberviolence as 'Victorian efforts to protect women from coarse language'.

Turning to statistics for a little while, it becomes possible to see the extent of the problem. Research reveals that approximately nine million women have experienced a serious form of cyber violence since the age of fifteen, and that their online harassers are more likely to be men $(61 \%)$. Women are significantly more likely to be abused online than men, with feminine usernames receiving more online threats than masculine usernames. The consequence of this is that one in five women feel that the internet is inappropriate for them; online misogyny results in the silencing of women (UN 2015). Research conducted by the digital security firm Norton has also shown that one in seven women - a figure which rises to one in four for the under 30 s - had received general threats of physical violence. Women under 30 were overrepresented in every category of harassment, ranging from trolling to threats of rape and death (Norton 2016).

\section{Framing the Problem}

It is useful to re-visit Kelly's (1988) idea of a 'continuum of violence', which sought to explore commonalities between women's experiences of male violence in its myriad forms. Crucially, this approach acknowledged difference in both experience of and responses to violence. To use, for a moment, the language of the internet, experiences of abuse vary widely from name-calling, trolling, sexting and shaming, through to death threats and similarly receive very different responses in the public and within law. Kelly developed 
the concept of a continuum of violence as a way of showing how the abuse that women experience as children and adults is not necessarily reflected in legal codes or in the conventional formulations of social scientists. She suggests that our common-sense (and very often legal) definitions of violence are, in fact, 'male definitions' restricted to the most extreme and public forms. We need to be mindful of this when constructing new legislation to deal with cyberabuse. Indeed, to say that violence itself is gendered, is not a particularly controversial statement, not just in that it is most likely to be perpetrated by men but because the very essence of violence, has, through language and culture, been masculinised, understood as a natural, biological aspect of being and becoming a man. As such, we are less likely to question, or even notice, violent actions perpetrated by a man.

Arguably, the language of cyber abuse does not reflect the real harms experienced by women and girls; instead, their experience is minimised, rendered invisible or recuperated in many of the stories we are presented with. Ken Plummer's (1995) work, on telling sexual stories, is of interest in this respect. He suggests that whenever we are presented with a new (or old) sexual story we need to ask ourselves:

- whose stories right now are we able to hear?

- who is recognised as a legitimate victim of cyber abuse?

- whose story are we not yet able to hear and why?

Part of the dominant story of cyberabuse includes common myths related to gendered violence. Kelly (1988) lists the myths people employ in order to lay the blame at the feet 
of victims: they enjoy it, they ask for it, they exaggerate. Many of these myths are used now in relation to cyberabuse. Such myths perpetuate stereotypes of women as being passive victims of abuse, hysterical and provokers of violence.

It is incumbent on all of us to find ways for those who have experienced online abuse to 'tell their stories' in such a way as to produce mutual recognition and support. Sensitivity to the context in which stories are told, the discourses which produce particular stories and an audience primed to listen, is a necessary counter to the danger of missing out the complexities of storytelling and story hearing (Furedi 2003). Being willing to challenge the emerging dominant discourse surrounding cyber-abuse thus assumes great importance.

\section{'Get Over it, it's just the internet'}

Despite suggestions that gender abuse online isn't a serious matter (see O'Neill 2011), it needs to be understood as a serious social problem. Online threats of rape, death and stalking, not only impact on the emotional lives of women but, when considering legal fees, health care, efforts in data protection and missed earnings due to stress, also constitute a considerable financial burden. It also has an adverse effect on the exercise of free speech, who feels able to speak and what we can hear.

Cyber violence shows itself in myriad forms: hate speech; stalking; hacking; image manipulation; threats; privacy violation; cyber bullying and online pornography. The internet more generally facilitates trafficking and the sex trade. Women are guilty of many of these forms of abuse (their targets often other women, which is how hegemonic 
institutions such as patriarchy work), just as they are in wider society but the vast majority of these abuses are committed by men and we should not overlook that fact. Men can also find themselves to be victims of these crimes but their gender and sexuality are rarely the target for such vitriol. Neither is this a problem confined to the 'first world'. These digital vehicles for violence can instantly transmit across time and space to billions of people; we are facing a global pandemic. However, I do not want to blame these new technologies. As Jewkes (2012) has pointed out in relation to child sex abuse, blaming the internet masks the underlying nature of the problem, a patriarchal/misogynistic culture.

Given that more and more people's lives are embedded in the internet, suggestions to close Facebook accounts or switch off the computer are unhelpful and once again render the victim responsible for what happens to them. As an emerging form of MVAWG, online abuse is limiting women and girls' ability to make the most of the opportunities afforded by the internet and new technologies more generally, in other words, women are being denied their human rights. There are also suggestions that increasingly it is becoming part of intimate partner violence and sexual harassment (WHO 2013)

\section{What Lies Beneath: causes of online abuse}

The internet, of course, does not exist in a vacuum and it is vital to consider this in relation to other factors external to the internet which allow for such abuse. One aspect it is important to consider, is the contribution made by increased access to pornography. In fact, there has been much debate about the relative harm of pornography and its contribution to 
the actual abuse experienced by women and girls and there is not the space to replicate that here (see Dworkin 1981, Dines 2010). Figures vary but some studies suggest as much as thirty percent of internet traffic is pornography (Optenet 2010), with over eighty percent of top-rated porn being violent and over ninety percent of that violence directed at women (Bridges and Wosnitzer 2010). Many studies suggest that after viewing, men display less empathy for rape victims. Boys aged 12-17 are among the largest consumers of internet porn and the first images they may see of sex often involve violence against women (Ybarra et al 2011). Such figures cannot be considered as anything other than worrying.

\section{Making tolerable the intolerable: constructions of masculinity and femininity}

Mainstream media also has a role to play in the acceptance and prevalence of online abuse. Men's magazines such as Nuts, Loaded, Zoo and others have a role to play in the normalisation and legitimisation of (the language of) sexual violence. Studies have shown how many find the language used in 'lads' magazines and testimonies of abuse by convicted rapists indistinguishable (Horvath et al 2011). Popular (re)presentations of hegemonic ideas and ideals about (hetero)sexuality are reinforcing binaries throughout such mainstream media. The effect is one of normalising sexual violence; dangerous distinctions between porn and 'nearly porn' contribute to making tolerable the intolerable.

Recent media 'debates' about rape further add to such constructions. For instance the US Republican, Todd Akin, when engaging in debates around abortion and rape drew (inane) distinctions between legitimate rape, claiming that in real rape situations a woman's body 'closes down' making it impossible for her to become pregnant. Ironically, Respect MP 
George Galloway, in defence of Julian Assange, stated that sleeping with an unconscious woman was simply a matter of 'bad sexual etiquette'. Conservative MP and former Justice Secretary Ken Clarke talked about 'serious' rape (presumably as distinct from 'not serious rape'?). Television regulars such as Judy Finnegan and Michael Buerk, commenting on the victim of rapist Ched Evans, qualified the harm she experienced by stating it was 'not violent rape' and that she was 'drunk and deserved no credit'. When we are presented with such distinctions time and time again, it becomes very easy to leave them unchallenged.

However, these ideas about gender, sexuality and violence impact on social responses to gender abuse and so we must challenge them. Over half (56\%) of those surveyed (in Britain) think that there are some circumstances where a person should accept responsibility for being raped. Of those people the circumstances are:

- Performing another sexual act on them (73\%)

- Getting into bed with a person $(66 \%)$

- Drinking to excess / blackout (64\%)

- Going back to theirs for a drink (29\%)

- Dressing provocatively (28\%)

- Dancing in a sexy way with a man at a night club or bar $(22 \%)$

- Acting flirtatiously (21\%)

- Kissing them $(14 \%)$

- Accepting a drink and engaging in a conversation at a bar (13\%) [Haven Report 2010] 
Neither is academia exempt from reproducing dominant ways of thinking about gender and violence. Violent men, such as rapists, despite being shown by numerous studies to be normal, everyday men in the main (Stanko 1990), are frequently presented as 'born criminals or, more usually, placed within a multi-factorial framework that gives biological factors pride of place' (Howe 2008: 80). In other words they are presented to us aberrant, pathological men, making a clear and unhelpful distinction between violent men and normal men. In this way we are not asked to challenge or question the dominant masculine subjectivities/sexualities our culture has produced. Instead, we excuse, tolerate, normalise and perhaps even fetishise rape, Brownmiller's (1976) 'rape culture' in action. In such a context, it is perhaps not surprising the gendered abuse online has been tolerated to the extent it has.

\section{What has the EU ever done for us?}

On top of these cultural contributions to the acceptance and tolerance of abuse against women on and offline, we have a turbulent political climate ahead. In the UK between 2010 and 2014, under Conservative leadership, 32 domestic violence refuges were closed due to funding cuts forced onto local authorities. Many services are still under considerable financial pressure, having to fall back on reserve funding just to survive. EU funding for such charities, however, has helped in the fight against all forms of violence against women. The UK has received a considerable sum, in fact, from the EU; a total of $£ 38$ million (€48million) to improve the rights of victims, and to fight domestic violence. Britain's involvement in tackling the ongoing slave trade is a result of EU directives in anti-trafficking. The Istanbul Convention, though distinct from the EU, being a Council of 
Europe convention on preventing and combating violence against women, is based on close work with the EU. This has produced much important research into MVAWG and has also led to various protective measures for victims. The European Court of Justice (ECJ), an EU body that draws upon the case law of the European Court of Human Rights, and its Convention, has also been instrumental in the fight against such violence in the UK. This is but a very brief detailing of some of the vital measures and resources coming into the UK from the EU. Thus, 'Brexit' will entail Britain formally cutting the link between the ECJ and the UK and many of the other EU initiatives. Given the historic attitudes of this Conservative government towards MVAWG, the future does not look particularly rosy and we will need to be on our mettle to continue the battle against online misogyny. Now, more than ever, is a time for joined-up thinking, both across disciplines and across national boundaries. Seeking to combat such a widespread wrong in an individual state is surely irrational, when sharing resources has proved so helpful in the past.

All is not gloom however, the self-same online spaces which are such a difficult arena for many women, also offer opportunities for challenges and resistance. Online feminist activism goes some way to alleviate the effects of sexual violence in both the on and offline world. Labour, Conservative and Liberal Democrat politicians managed to come together to Reclaim the Internet (2016). Journalists throughout the OSCE region have worked together online to challenge the abuse faced by female journalists (2015). Last year the government launched an anti-trolling website, Stop Online Abuse, in an attempt to support victims of online abuse, in particular women and LGBT people.

\section{Conclusion}


There is no doubt that we live in a violent world, one were several countries at any time are ravaged by war. There is no doubt too, that anyone inhabiting a woman's body is at serious risk of experiencing violence at some point in their lifetime; globally, violence against women is an insidious and systemic problem. Online space is no less fraught with danger for women who dare to put their head above the parapet and speak out. It is clear, too, that in the popular imagination, online abuse conjures up a particular public story, which frequently presents the violence experienced by women online as not significant. Jamieson (2002) argues that typically, pervasive public stories originate with people in powerful positions within powerful institutions. There is a danger that this very real social problem will slip under the radar because of the dominant ways of thinking and talking about the internet and about violence more generally. With each new generation there needs to come, perhaps, a new and slightly different articulation of the story of gender abuse, a different social understanding, whilst never entirely losing other understandings (Todd 2013).

The language used to describe violence is political and it is where we begin to understand and respond to the problem. Overtime these terms and definitions often shift and develop to incorporate new understandings, to be inclusive of more people, they become, perhaps, more sophisticated. We are at a stage where the language used to talk about online gender abuse is in its infancy, its abstractness, its gender neutrality, serving to reinforce patriarchal stereotypes about gender violence. Overtime, hopefully, the ways in which we talk about cyberabuse will mature to reflect the experiences of those have been subjected to it. 
To continue this fight, it is imperative that links are made between online assault and rape/murder, one may not necessarily lead directly to the other but they are composite parts of the same problem. The daily normalisation of the suggestion that women are 'other', objects, inferior, to be seen through a default male gaze, is dangerous. We also need to make the connection between gender abuse and the online racist and homophobic abuse which is also on the rise. The only way to combat online violence against women is to challenge gender inequity in wider society. If we're saying that it's appropriate for men to assume power and ownership over women they don't know in public, to effectively silence them, then we're also saying something much wider about gender relations. We need to think very carefully about how that is going to be done in the coming political and cultural shifts we will inevitably witness.

\section{References}

Alcoff, L and Gray, L (1993) 'Survivor Discourse: Transgression or Recuperation?', in Signs: Journal of Women in Culture and Society 18(2): 260-6.

Beard, M. (2014) “'Oh Do Shut Up Dear!' The Public Voice of Women', London Review of Books lecture, BBC 4, 15.3.2014.

Beauvoir, S de (1993) The Second Sex. New York: Vintage Press.Berns, N (2001)

'Degendering the Problem and Gendering the Blame: Political Discourse on Women and Violence', in Gender \& Society 15(2): 262-281.

Bridges, A and Wosnitzer, R (2010) 'Aggression and sexual behaviour in best-selling pornography: A content analysis update', Violence Against Women 16(10): 1065-1085. Brownmiller, S (1979) Against Our Wills: Men, Women and Rape. London: Penguin. 
Cameron, D and Frazer, E (1987) The Lust to Kill: A Feminist Investigation of Sexual Murder. Cambridge: Polity Press.

Cameron, D (1992) Feminism and Linguistic Theory, $2^{\text {nd }}$ edn. London: Macmillan. Coates, J (1993) Women, Men and Language, $2^{\text {nd }}$ edn. London: Longman.

Corrin, C (ed) (1996) Women in a Violent World: Feminist Analyses and Resistance Across 'Europe'. Edinburgh: Edinburgh University Press.

Dines, G (2010) Pornland: How Pornography has Highjacked our Sexuality. Boston: Beacon Press.

Dworkin, A (1981) Pornography: Men Possessing Women. New York: Perigee.

Edwards, A (1986) 'Male Violence in Feminist Theory: An Analysis of the Changing Conceptions of Sex/Gender Violence and Male Dominance', in J. Hanmer and M. Maynard (eds) Women, Violence and Social Control. London: Macmillan.

Fineman, M. (1994) 'Preface', in M. Fineman and R. Myktiuk (eds) The Public Nature of Private Violence: The Discovery of Domestic Abuse. London: Routledge.

Furedi, F. (2003) Therapy Culture: Cultivating Vulnerability In An Uncertain Age. London: Routledge.

Guardian, (2016) The Web We Want https://www.theguardian.com/technology/series/theweb-we-want

Horvath, M and Hegarty, P (2011) 'Are Sex Offenders and Lads' Mags Using the Same Language?' http://www.mdx.ac.uk/news/2011/12/are-sex-offenders-and-lads-magsusing-the-same-language

Howe, A (2008) Sex, Violence and Crime: Foucault and the 'Man' Question. London: Routledge. 
Jamieson, L (2002) Intimacy: Personal Relationships in Modern Societies. Cambridge: Polity Press.

Jewkes, Y (2012) 'Reconstructing the Sexual Abuse of Children: 'cyber-paeds', panic and power', in Sexualities 15(8): 934-952.

Kelly, L (1988) Surviving Sexual Violence. Cambridge: Polity Press.

Letherby, G (2003) Feminist Research in Theory and Practice. Buckingham: Open University Press.

Malleson, A (2002) Whiplash and Other Useful Illnesses. Montreal: McGill-Queen's University Press.

Mulvey, L (1975) 'Visual Pleasure and Narrative Cinema', in Screen 16(3): 6-18.

Norton (2016) Online Harassment: The Australian Woman's Experience.

https://phoenix.symantec.com/Norton/au/online-harassment-experience-

women/assets/A4_Norton_infographic_Online_Harassment_Against_Women.pdf

accessed 13.6.2016.

Oakley, A (1981) Subject Women. Oxford: Martin Robertson.

Optenet (2010) 'More than One Third of Web Pages are Pornographic', http://www.optenet.com/en-us/new.asp?id=270 accessed 15.6.2016.

O’Neill, B (2011) 'The Campaign to 'Stamp Out Misogyny Online' Echoes Victorian Efforts to Protect Women from Course Language', (blog.telegraph.co.uk) November $7^{\text {th }}$ 2011 http://www.telegraph.co.uk/opinion/

OSCE (2015) 'New Challenges to Freedom of Expression: Countering Online Abuse of Female Journalists' Office of the Representative on Freedom of the Media, Vienna http://www.osce.org/fom/220411?download=true 
Phillips, D and Henderson, D (1999) 'A Discourse Analysis of male violence against women', in American Journal of Orthopsychiatry 69(1):116-21.

Plummer, K (1995) Telling Sexual Stories: Power, Change and Social Worlds. London:

Routledge.

Povey, D (2005) 'Crime in England and Wales 2003/2004: Supplementary Volume 1:

Homicide and Gun Crime. Home Office Statistical Bulletin No. 02/05. Home Office.

London; Department of Health (2005) Responding to Domestic Abuse. DH. London.

(from 'Statistics on Domestic Violence': www.womensaid.org.uk)

Reclaim the Internet (2016) http://www.reclaimtheinternet.com/

Richardson, D and May, H (1999) 'Deserving Victims?: Sexual Status and the Social

Construction of Violence', in Sociological Review 47(2): 308-331.

Romito, P (2008) A Deafening Silence: Hidden Violence against Women and Children.

Bristol: Policy Press.

Sheller, M and Urry J (2003) 'Mobile Transformations of 'Public' and 'Private' Life' in

Theory, Culture and Society 20(3): 107-125.

Smart, C (1989) Feminism and the Power of Law. London: Routledge.

Smart, C (1995) Law, Crime and Sexuality: Essays in Feminism. London: Sage.

Smith, D (1988) The Everyday World as Problematic: A Feminist Sociology. Milton

Keynes: Open University Press.

Spender, D (1980) Man-Made Language. London: Routledge \& Kegan Paul.

Stanko, E (1985) Intimate Intrusions: Women's Experience of Male Violence. London:

Routledge. 
Stanko, E (1990) Everyday Violence: How Women and Men Experience Sexual and Physical Danger. London: Pandora.

Todd, M (2013) ‘Blue Rinse Blues? Older Lesbians' Experiences of Domestic Violence’ in T Sanger and Y Taylor (eds) Mapping Intimacies: Relations, Exchanges, Affects. London: Palgrave Macmillan.

United Nations Broadband Commission (2015) 'Cyber Violence Against Women and Girls: A World-Wide Wake-Up Call’ http://www.unwomen.org/ /media/headquarters/attachments/sections/library/publications /2015/cyber_violence_gender\%20report.pdf accessed 15.6.2016.

Walby, S (1990) Patriarchy at Work. Cambridge: Polity Press.

Walby, S and Allen J (2004) 'Domestic Violence, Sexual Assault and Stalking: Findings from the British Crime Survey', Home Office Research Study 276, Home Office Research, Development and Statistics Directorate.

World Health Organization (2013) 'Global and regional estimates of violence against women: prevalence and health effects of intimate partner violence and non-partner sexual violence', Department of Reproductive Health and Research, London School of Hygiene and Tropical Medicine, South African Medical Research Council, WHO, Switzerland. Ybarra, M, Mitchell, K, Hamburger, M, Diener-West, M and Leaf, J (2011) 'X-Rated Material and Perpetration of Sexually Aggressive Behaviour Among Children and Adolescents: Is There a Link?', in Aggressive Behaviour 37: 1-18.

Yllo, K and Bograd, M (eds) (1988) Feminist Perspectives on Wife Abuse. London: Sage. 
